\title{
Bench Set Impact Analysis on Fail-Safe Condition of Fail to Closed Type Control Valve with Spring- Diaphragm Actuator
}

\author{
1,2 Yoki Andriawan Ramdan \\ ${ }^{1}$ PT. Clariant, Tangerang - Indonesia \\ ${ }^{2}$ Mechanical Engineering Department \\ Swiss German University \\ Tangerang City, Indonesia \\ yokiandriawan.ramdan@clariant.com
}

\author{
*Dena Hendriana \\ Master of Mechanical Engineering \\ Swiss German University \\ Tangerang City, Indonesia \\ dena.hendriana@sgu.ac.id \\ Gembong Baskoro \\ Master of Mechanical Engineering \\ Swiss German University \\ Tangerang City, Indonesia \\ gembong.baskoro@sgu.ac.id
}

\author{
Henry Nasution \\ Master of Mechanical Engineering \\ Swiss German University \\ Tangerang City, Indonesia \\ henry.nasution@sgu.ac.id
}

\begin{abstract}
Control valve is one of key elements in processing of a chemical industry and it is one of its important functions is as a flow control of chemical process. The accuracy of control valve opening or traveling is proportional to flow capacity. On the other hand, a leakage of a control valve on its failed position especially for Air to Open-Fail Closed (ATO-FC) type valve can become a disaster. One of critical parameters in Control Valve that impacts to performance and fail-safe position is Bench set range spring in valve's actuator. This work analyzed this Bench set range impact to the fail-safe position. The force in spring is defined by control valve specification verified by force balance method of control valve. Then the impact of bench set range was analyzed by displacement of spring from spring force equation. At the end, the outcome is displacement data in correlation to the change of bench set range. It helps the repair technician on the maintenance workshop of permissible range when they adjust the bench set range by adjusting spring compression.
\end{abstract}

Keywords-control valve, flow control, bench set, spring damper

\section{INTRODUCTION}

Control valve represents an important element of the control systems and it is a non-linear element, characterized by the complexity of the mechanical construction and the hydraulic phenomena. One important problem of the engineering control is the fail-safe position of the control valve. This work models and simulates the fail-safe condition of control valves. The fundament of mathematical model [1] for the fail-safe position of control valve is represented by equation (1):

$$
\Delta \mathrm{P}_{\text {shutoff }}=\mathrm{P}_{1 \max }-\mathrm{P}_{2 \text { min }}
$$

This work focuses on globe valve as shown in Fig. 1 with single spring diaphragm-actuator type. It will be used as an example of calculation during modelling impact of bench set range. On the repair side, a highly skilled and trained valve technician can perform minor control valve repairs from simple re-packs to major overhauls including complete rebuilds of the control valve body assembly, actuator, and instrumentation. Using our machining equipment, our machinists can resurface gasket landings and re-thread washed out valve bodies eliminating the need to remove the control valve body from the pipeline.

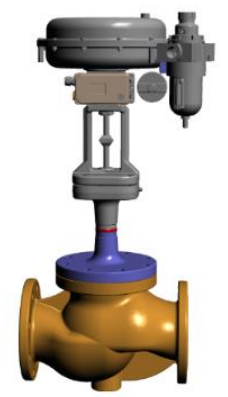

Fig. 1.3D drawing of control valve

After all repairs are made, including re-stroking the control valve and actuator assemblies and re-calibrating instrumentation, our valve technicians will perform diagnostics to document and then verify that the valve's performance is within acceptable parameters. During repair, if the technician does not understand the impact on the bench set range setting, the fail-safe position would not be as per expected. Specially for valve type fail to close, it will generate leakage due to the valve cannot fully shut off. Example application of proportional valve for hot press machine has been studied in [2].

This work is to determine and give modeling on Bench set range setting using spring and damper method. Springs

${ }^{*}$ Corresponding Author|Dena Hendriana | Email: dena.hendriana@sgu.ac.id

Tangerang - Indonesia, 28 September 2020 
that are stretched or compressed around their equilibrium position is proportional to applied force $\mathrm{F}$ following Hooke's law. The restoring force F exerted by the spring is given by:

$$
\mathrm{F}=\mathrm{kx}
$$

where $\mathrm{k}$ is the spring constant and $\mathrm{x}$ the measured displacement from the equilibrium position. Bench set range is determined by the spring rate of the actuator failsafe range spring(s). It is expressed for a given actuator (with its particular diaphragm area) by the actuator's pneumatic "Load" pressure that opposes the range spring and gives the theoretical pressures at beginning of stroke and completion of full stroke.

\section{TYPICAL FAIL TO CLOSE CONTROL VALVE}

\section{A. Categorizing Control Valve by Fail-Safe Position}

The control valve is an element of the control system and it is the most widespread control element in the field of chemical and petrochemical industry. The industrial control valve contains an electronic pneumatic converter, a pneumatic actuator with membrane and a control element with a seat.

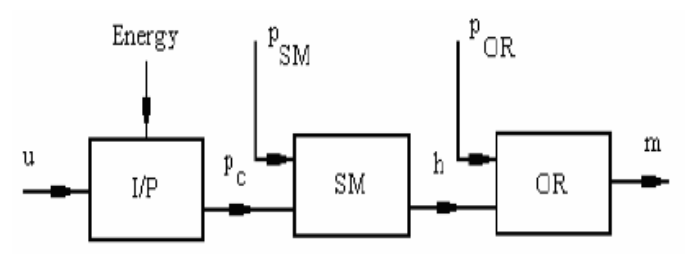

Fig. 2. Structure of control valve

Fig. 2 shows the significance of the variables and the subsystems: I/P - electro-pneumatic converter; SM actuator; OR - control element; u - electrical signal command; pc - pneumatic signal command; $h$ - the stroke of the actuator; pSM - disturbances associated [3]. The control valve is categorized also by its fail-safe position which will only have two different type. The first type is Fail to Close (FC), meaning if the energy source to drive the control valve either electro or pneumatic is cut off, the valve shall be in fully closed position. The second type is Fail to Open (FO), which opposite to FC, FO type shall be in fully open position whenever the energy source is cut off.

For Control valve with pneumatic actuator, the FC type have distinguished also as Air to Open (ATO) valve, see Fig. 3, because its opening will work when instrument air from positioner is flow in to diaphragm membrane as loading pressure, then it will move the stem up depending the loading pressure, it will creating force against the spring force.

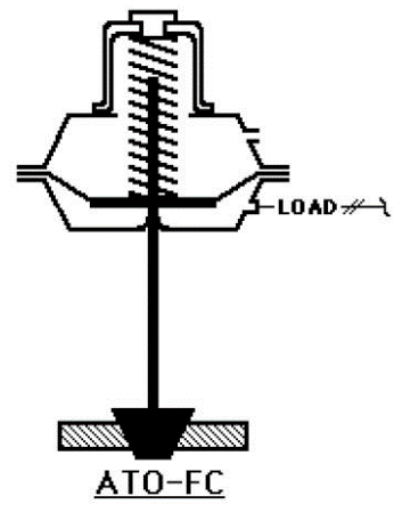

Fig. 3. Freebody diagram ATO-FC type control valve

\section{B. Force Balance of ATO-FC Type Control Valve}

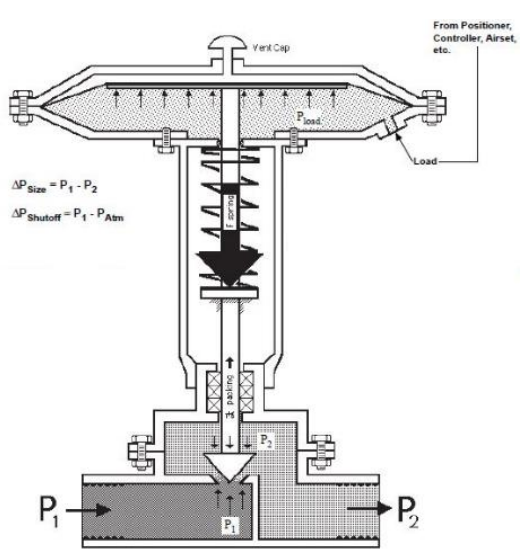

Fig. 4. Detail of ATO-FC valve

The force balance equation from a typical ATO-FC type control valve is shown in Fig. 4, as follows:

$$
\begin{gathered}
\sum \text { Fup }=\sum F \text { down } \\
\mathrm{P}_{1} * \mathrm{~A}_{\text {Port }}+\mathrm{P}_{\text {Load }} * \mathrm{~A}_{\text {Diaph }}+\mathrm{F}_{\mathrm{k} \text { Packing }}=\mathrm{F}_{\text {Spring }}+\mathrm{P}_{2} * \mathrm{~A}_{\text {plug }}
\end{gathered}
$$

\section{Fail Safe Position for ATO-FC Type Valve}

From equation (1) and (3), shut off condition of ATOFC is expected on fully closed position. In ideal condition $\mathrm{P}_{2}$ shall be equal to 0 bar. $\mathrm{P}_{\mathrm{Load}}$ also shall be equal to 0 bar. $F_{k}$ Packing will be very small, so we can ignore it. At the end, only $\mathrm{P}_{1} * \mathrm{~A}_{\text {Port }}$ will be on the maximum against the $\mathrm{F}_{\text {Spring }}$ to influence valve on shut off condition to close properly. If valve can close properly, it means no leakage. The ideal equation for shut off condition will be:

$$
\mathrm{P}_{1} * \mathrm{~A}_{\text {Port }}=\mathrm{F}_{\text {Spring }}
$$

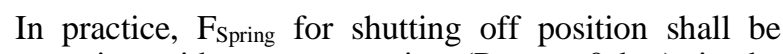
when spring without compression $\left(\mathrm{P}_{\text {Load }}=0\right.$ bar $)$, in the other word when length of spring is equal of its $l_{0}$ (unstretched length). This $\mathrm{F}_{\text {Spring }}$ should be bigger than $\mathrm{P}_{1} *$ $A_{\text {Port }}$ to have a confident level that valve can really close properly during shut off condition. Therefore $\mathrm{P}_{1}$ become 
important parameter that has to be stated on the specification when we need to purchase a control valve.

Based on $\mathrm{P}_{1}$ requirement and equation (2), we can calculate requirement for $\mathrm{k}$ (spring rate) and $\mathrm{l}_{0}$ (unstretched length) of spring(s).

\section{CASE STUDY}

A. Proving Fail-Safe Position Requirement from an Example of Control Valve Specification

On the real case for this work, we will analyze a control valve with following specification:

- Samson Globe Control Valve Type 3241-7 DN 40, Body cast steel 1.0619, PN 16, Flange RF, Seat \& Plug 1.4006, Kvs 80, Insulating section c/w

- $\quad$ Pneumatic Actuator Type 3277; $350 \mathrm{~cm}^{2}, 1.4-2.3$ bar, Air fail close

- Hart Positioner Type 3730-31; Ex ia IIC T6, With LCD \& Autotune, 4-20 mA, IP 65, Hart communication, 2 gauge and airset.

The relevant data from above specification for this work is Bench Set range $1.4-2.3$ bar, ATO-FC type with $A_{\text {Diaph }}=350 \mathrm{~cm}^{2}$. From the manual and datasheet of the control valve, we got following details in below Table 1:

TABLE I

SPECIFICATION DATA OF EXAMPLE CONTROL VALVE

\begin{tabular}{ccccc}
\hline $\begin{array}{c}\mathrm{P}_{1} \\
(\mathrm{bar})\end{array}$ & $\begin{array}{c}\mathrm{A}_{\text {Diaph }} \\
\left(\mathrm{cm}^{2}\right)\end{array}$ & $\begin{array}{c}\text { Rated travel } \\
(\mathrm{mm})\end{array}$ & $\begin{array}{c}\text { Max. travel } \\
(\mathrm{mm})\end{array}$ & $\begin{array}{c}\text { Bench range } \\
(\text { bar })\end{array}$ \\
\hline 22 & 350 & 15 & 15 & $1.4-2.3$ \\
\hline $\begin{array}{c}\mathrm{F}_{\text {spring in } 0 \mathrm{~mm} \text { travel }} \\
(\mathrm{kN})\end{array}$ & $\begin{array}{c}\mathrm{F}_{\text {spring in max. }} \\
(\mathrm{kN})\end{array}$ & $1_{0}(\mathrm{~mm})$ & $\emptyset$ seat $(\mathrm{mm})$ \\
\hline 4.9 & 8.05 & 88.3 & 48 \\
\hline
\end{tabular}

From above data, we can calculate following

$$
\begin{aligned}
A_{\text {Port }}=48^{2} * \pi / 4 & =1.81 \times 10^{-3} \mathrm{~m}^{2} \\
\mathrm{P}_{1 \max \text { in } \mathrm{N} / \mathrm{m} 2} & =2.2 \times 10^{6} \mathrm{~N} / \mathrm{m}^{2} \\
\mathrm{P}_{1} * \mathrm{~A}_{\text {Port }} & =3.98 \times 10^{3} \mathrm{~N}
\end{aligned}
$$

The result in equation (7) need to be compared with $F_{\text {Spring }}$ in $0 \mathrm{~mm}$ travel condition, which mention in data specification on Table 1. The data in the table for $F_{\text {Spring }}$ is bigger than $\mathrm{P}_{1} * \mathrm{~A}_{\text {Port }}$ as shown equation (8).

$$
F_{\text {Spring }}=4.9 \times 10^{3} \mathrm{~N}>3.98 \times 10^{3} \mathrm{~N}
$$

The result in equation (8) proves that the specification data can fulfill the requirement of fail-safe position of ATO-FC type valve as describe in section II.C.

\section{B. Bench Set Range Setting}

After verification has been done in section III.A, the work continues with the main objective to see the impact when we need to adjust the spring compression by spring adjustor as illustrated on Fig. 5. Adjusting spring is called Bench set range adjustment because it will impact to the working force of spring due to change of displacement $\mathrm{x}$ in equation (2).

In Table 1 , from the $F_{\text {Spring }}$ in $0 \mathrm{~mm}$ travel condition data we can see the initial compression of spring in shut off condition, which means it will be on very minimum compression. In another word this also means that we can get the initial displacement $\mathrm{x}$ if we know the $\mathrm{k}-$ the spring constant.

According to Sommerfeld [4-6], it is possible to show that for helical springs the longitudinal elastic constant $\mathrm{k}$ is given by:

$$
\mathrm{k}=\mathrm{G} \pi \mathrm{d}^{4} / 32 \mathrm{R}^{2} \mathrm{l}_{0}
$$

where $R$ is the coil radius, $l 0$ the natural length of the spring, $d$ the wire diameter and $G$ the shear modulus of the material of the wire from which the spring is made.

Additional data of spring is required in order to be able to calculate the spring constant by equation (9). From the work in our workshop, we can get additional spring data as below table:

TABLE II

ADDITIONAL DATA OF SPRING

\begin{tabular}{ccc}
\hline Coil radius $(\mathrm{mm})$ & Wire diameter $(\mathrm{mm})$ & $\begin{array}{c}\text { Shear modulus of } \\
\text { steel }\left(\mathrm{N} / \mathrm{m}^{2}\right)\end{array}$ \\
\hline 43.5 & 6.7 & $79 \times 10^{9}$ \\
\hline
\end{tabular}

From Table 1 and Table 2, we come up with spring constant value:

$$
\mathrm{k}=9.36 \times 10^{4} \mathrm{~N} / \mathrm{m}
$$

Then we can find the displacement $\mathrm{x}$ in $0 \mathrm{~mm}$ travel, by equation (2) which the result is

$$
\mathrm{X}=52.36 \mathrm{~mm}
$$

The result of equation (11) means the initial displacement $\mathrm{x}$ in the fail-safe position of ATO-FC type of control valve used for this work.

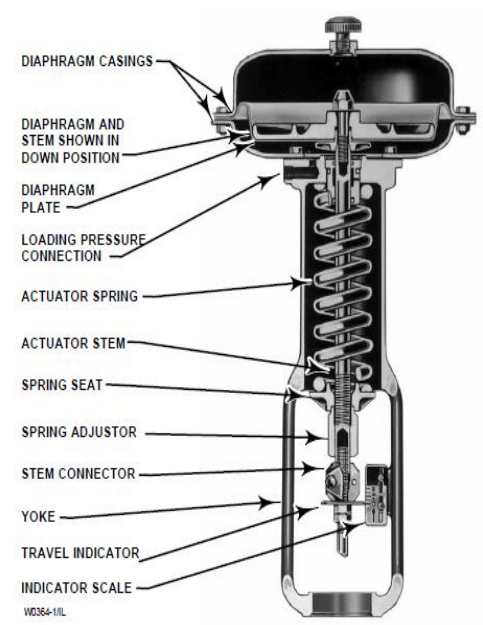

Fig. 5. Typical actuator of ATO-FC control valve [7] 
Now we can simulate the value of the $\mathrm{x}$ displacement changed by spring adjuster and the result can be seen by the trend in Fig. 6. The graph starts from initial displacement value of $\mathrm{x}=52.36 \mathrm{~mm}$, as per calculation still can handle $\mathrm{P}_{1}$ maximum pressure till 27.07 bar during shut off condition of control valve.

Increasing the displacement value means to compress more on the spring and therefore the $\mathrm{F}_{\text {spring }}$ can handle more pressure on $\mathrm{P}_{1}$ for shut off condition. However, this will be also increasing stiffness of spring and it will impact to throttling control that will need more pressure in $\mathrm{P}_{\text {load }}$ to actuator. Unfortunately, impact analyzing to throttling control is not part of this work.

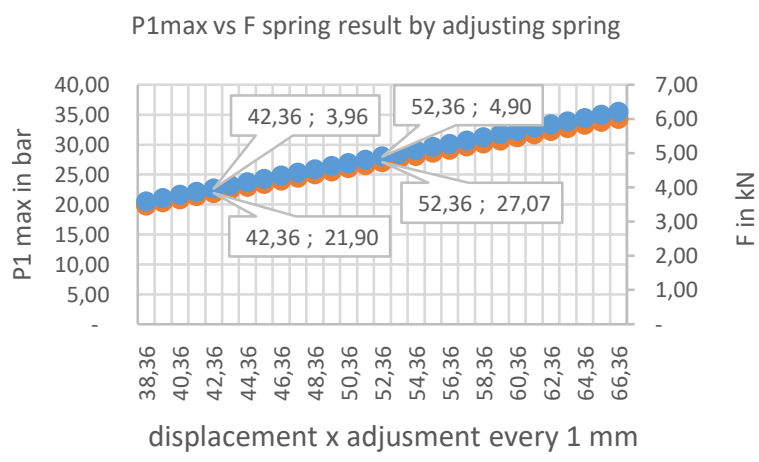

Fig. 6. $\mathrm{P}_{1 \text { max }}$ and $\mathrm{F}$ spring result by adjusting spring every $1 \mathrm{~mm}$

Decreasing the displacement value means reducing compression of the spring and therefore the $F_{\text {spring }}$ capabilities to handle pressure on $\mathrm{P}_{1}$ also decreases and the control valve condition is not valid as specification any more. The user of the control valve has to be aware that $\mathrm{P}_{1 \text { max }}$ also need to be reduced during applying the control valve in this kind of condition.

From the same trending, it can generate the linear equation as shown in Fig. 7 , for $F_{\text {spring }}$ impact by change the displacement:

$$
y=0.0936 x-6^{*} 10^{-14}
$$

While for $\mathrm{P}_{1}$ impact by change the displacement:

$$
\mathrm{y}=0.517 \mathrm{x}-1 * 10^{-13}
$$

\section{CONCLUSION}

Spring adjustment study of an ATO-FC type control valve shows the impact of the bench set range of respective control valve type. Whereby increase of displacement of spring, it will increase also the force of spring and increase capabilities of spring force to handle pressure inlet $\mathrm{P}_{1}$ at maximum during shut off condition of control valve.

\section{P1max vs F spring result by adjusting spring}

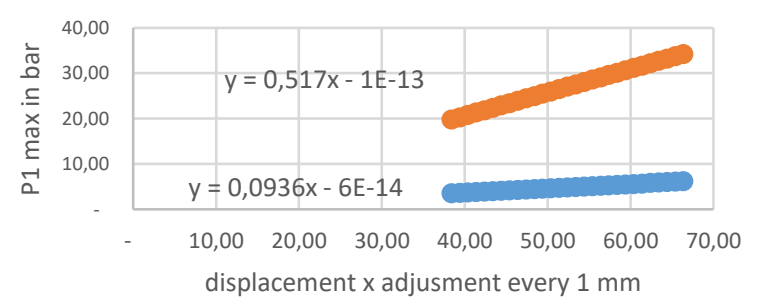

- $\quad$ P $\quad \mathrm{F} \ldots \ldots$.... Linear $(\mathrm{P}) \quad \ldots . .$. Linear $(\mathrm{F})$

Fig. 7. Linear equation for $\mathrm{F}_{\text {spring }}$ and $\mathrm{P}_{1}$

While in the opposite direction, the impact of reducing the displacement of spring in the ATO-FC control valve gives the reduction of the capabilities spring force to handle pressure inlet $\mathrm{P}_{1}$ at maximum. The new $\mathrm{P}_{1}$ at maximum value can become below of specification. Hence the spring adjustment setting shall be noticed. And the control valve performance shall be tested to avoid leakage during shut off condition.

Throttling performance of control valve is out of scope of current work and it is actually interesting topic for future work. The change of bench set range by changing the displacement of spring could impact also to the throttling performance of control valve.

\section{REFERENCES}

[1] Cashco, Basic Operation And Function of Control Valve, unpublished.

[2] W. Stevanus, H. J. Berchmans, A. A. Iskandar, "Pressure pattern improvement of proportional valve application on hot press machine using PID," $1^{\text {st }}$ Proceedings of The Conference on Management and Engineering in Industry (CMEI 2019)," vol. 1, pp. 44-48, Tangerang, Indonesia, August 2019.

[3] C A Triana and F Fajardo, "The influence of spring length on the physical parameters of simple harmonic motion", European Journal of Physics, 33(1), pp. 219-229, 2012.

[4] Hans D. Baumann, Control Valve Primer a user's Guide, ISA, 2009.

[5] A. Sommerfeld, Mechanics of Deformable Bodies (Lectures on Theoretical Physics vol 2), New York: Academic, pp 308-1, 1950.

[6] Emerson, Control Valves Handbook, USA: Emerson Process Management, 2005.

[7] C Patrascioiu, C Panaitescu, N Paraschivi, "Control Valves Modeling and Simulation," Proceedings of the $5^{\text {th }}$ WSEAS Int. Conf. on dynamical System and Control, pp. 63-68, La Laguna, Canary Islands, July 2009. 